\title{
Atributos químicos de áreas recuperadas após extração de seixo na Região
}

\section{Amazônica}

Soil chemical properties of recovered areas after gravel extraction in the Amazon Region

Atributos químicos de áreas recuperadas después de la extracción de guijarros en la Región

\section{Amazónica}

Recebido: 29/04/2021 | Revisado: 05/05/2021 | Aceito: 08/05/2021 | Publicado: 22/05/2021

Michel Sauma Filho

ORCID: https://orcid.org/0000-0002-6603-8445 Universidade Federal Rural da Amazônia, Brasil E-mail: michel.sauma@ufra.edu.br

Maria de Lourdes Pinheiro Ruivo ORCID: https://orcid.org/0000-0002-6222-5534 Museu Paraense Emílio Goeldi, Brasil E-mail: dpaulamt@hotmail.com

José Darlon Nascimento Alves

ORCID: https://orcid.org/0000-0003-1290-5598 Universidade Federal de Viçosa, Brasil E-mail: jose.darllon@hotmail.com

Heráclito Eugênio Oliveira da Conceição ORCID: https://orcid.org/0000-0002-5193-0916 Universidade Federal Rural da Amazônia, Brasil E-mail: agroheraclito@yahoo.com.br

Ismael de Jesus Matos Viégas ORCID: https://orcid.org/0000-0001-7212-1977 Universidade Federal Rural da Amazônia, Brasil E-mail: matosviegas@hotmail.com

Jairo Neves de Oliveira ORCID: https://orcid.org/0000-0002-6415-8101 Universidade Federal Rural da Amazônia, Brasil E-mail: jairoufracap22@gmail.com

Thifany Stella Cattossi de Miranda ORCID: https://orcid.org/0000-0001-5229-1311 Universidade Federal Rural da Amazônia, Brasil E-mail: thifanystella@gmail.com

José Antônio Lima Rocha Junior ORCID: https://orcid.org/0000-0001-6948-3969 Universidade Federal Rural da Amazônia, Brasil E-mail: juniorlimarocha4@gmail.com

Tayssa Menezes Franco ORCID: https://orcid.org/0000-0001-5460-1360 Universidade Federal de Viçosa, Brasil

E-mail: tayssa.menezes2015@gmail.com

Maria Leliane Pires da Costa ORCID: https://orcid.org/0000-0002-9383-8456 Universidade Federal Rural da Amazônia, Brasil E-mail: lelianepires.06@gmail.com

\begin{abstract}
Resumo
A região amazônica contribui expressivamente para o setor mineral brasileiro, entretanto, vem ocorrendo o aumento de áreas degradadas por mineração. Diante disso, o objetivo da pesquisa foi avaliar o efeito do uso da revegetação nos atributos químicos do solo em área sob a ação de extração de seixo na Amazônia. O experimento foi conduzido em uma área de mineração de seixo em Capitão Poço - PA. O delineamento experimental usado foi em blocos ao acaso, em parcelas subdivididas. As parcelas foram constituídas de dois tratamentos: calagem + escarificação e sem calagem e sem escarificação. As subparcelas foram compostas de cinco tratamentos: 1) plantio de mudas de sete espécies +

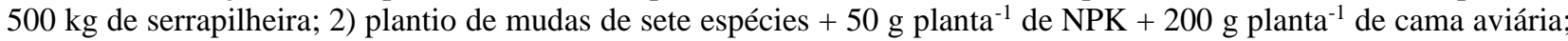

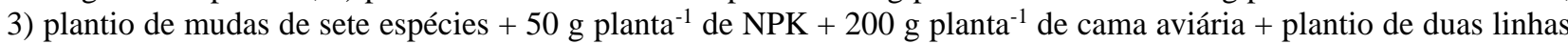
de feijão-caupi entre as linhas das sete espécies; 4) plantio de mudas de sete espécies $+50 \mathrm{~g} \mathrm{planta}^{-1} \mathrm{de} \mathrm{NPK}+200 \mathrm{~g}$ planta $^{-1}$ de cama aviária $+500 \mathrm{~kg}$ de topsoil e 5) regeneração natural. Em geral, os teores de MOS, P e K, no solo
\end{abstract}


construído foram inferiores se comparados com os valores obtidos na área de floresta secundária. Além disso, verificou-se redução dos teores de $\mathrm{Al}$ e $\mathrm{Na}$ nos solos construídos. Dessa forma, o uso da técnica de revegetação mostrou-se promissora, porém é necessário o acompanhamento em longo prazo.

Palavras-chave: Agregados do solo; Capitão Poço; Matéria orgânica do solo; Solos amazônicos.

\begin{abstract}
The Amazon region contributes significantly to the Brazilian mineral sector. However, there has been an increase in areas degraded by mining. Therefore, the objective of the research was to evaluate the effect of the use of revegetation on the soil chemical properties in an area under gravel extraction in the Amazon region. The experiment was carried out in a gravel mining area in Capitão Poço - PA. The experimental design used was in randomized blocks, in subdivided plots. The plots consisted of two treatments: liming + scarification and without liming and without scarification. The subplots were composed of five treatments: 1) planting seedlings of seven species $+500 \mathrm{~kg}$ of litter; 2) seedlings of seven species $+50 \mathrm{~g} \mathrm{plant}^{-1}$ of NPK $+200 \mathrm{~g} \mathrm{plant}^{-1}$ of poultry manure; 3 ) seedlings of seven species + $50 \mathrm{~g}_{\text {plant }}{ }^{-1}$ of NPK $+200 \mathrm{~g}$ plant $^{-1}$ of poultry manure + cultivation of two cowpea lines between the seven species lines; 4) planting seedlings of seven species $+50 \mathrm{~g} \mathrm{plant}^{-1}$ of NPK $+200 \mathrm{~g} \mathrm{plant}^{-1}$ of poultry manure $+500 \mathrm{~kg} \mathrm{de}$ topsoil and 5) natural regeneration. In general, MOS, P and K levels in the built soil were lower compared to the values obtained in the secondary forest area. In addition, there was a reduction in $\mathrm{Al}$ and $\mathrm{Na}$ levels in the constructed soils. Thus, the use of the revegetation technique proved to be promising, however, long-term follow-up is necessary.

Keywords: Soil aggregates; Capitão Poço; Organic soil matter; Amazonian soils.
\end{abstract}

\title{
Resumen
}

Amazonia contribuye al sector minero brasileño, sin embargo, ha habido un aumento de áreas degradadas por la minería. Por eso, el objetivo de la investigación fue evaluar el efecto del uso de la revegetación sobre los atributos químicos del suelo en una zona de extracción de guijarros en la Amazonia. El experimento tuvo lugar en Capitão Poço - PA. El diseño experimental utilizado fue en bloques al azar, en parcelas subdivididas. Las parcelas consistieron en dos tratamientos: encalado + escarificación y sin encalado y sin escarificación. Las subparcelas estuvieron compuestas por cinco tratamientos: 1) plantación de plantallas de siete especies $+500 \mathrm{~kg}$ de hojarasca; 2) plantación de plantallas de siete especies $+50 \mathrm{~g} \mathrm{NPK}$ plant $^{-1}+200 \mathrm{~g}$ de hojarasca aviar; 3) plantación de plantallas de siete especies $+50 \mathrm{~g}$ planta $^{-1}$ de NPK + $200 \mathrm{~g}_{\text {planta }}{ }^{-1}$ de hojarasca aviar + plantación de dos líneas de caupí entre las líneas de las siete especies; 4) plantación de plantallas de siete especies $+50 \mathrm{~g} \mathrm{planta}^{-1} \mathrm{de} \mathrm{NPK}+200 \mathrm{~g} \mathrm{planta}^{-1}$ de hojarasca aviar +500 $\mathrm{kg}$ de tierra vegetal y 5) regeneración natural. En general, los niveles de MOS, P y K en el suelo construido fueron menores en comparación con los valores obtenidos en el área de bosque secundario. Además, hubo una reducción en los niveles de Al y Na en los suelos construidos. Por lo tanto, el uso de la revegetación demostró ser prometedor, pero es necesario un seguimiento a largo plazo.

Palabras clave: Agregados de suelo; Capitão Poço; Materia orgánica del suelo; Suelos amazónicos.

\section{Introdução}

O Brasil apresenta uma grande biodiversidade em recursos naturais, entre eles podem-se destacar os recursos minerais. A extração e comércio de minérios contribuem expressivamente para a balança comercial do Brasil. Em 2020, o faturamento do setor mineral brasileiro foi de 209 bilhões de reais, aumento de $36 \%$ em relação ao ano anterior (IBRAM, 2021).

A região norte, especialmente o Pará é responsável por boa parte da extração de minérios, sendo a mineração uma das atividades do estado com grande investimento. O Pará é responsável por $46 \%$ da produção nacional de minérios, com faturamento de 97 bilhões de reais em 2020 (IBRAM, 2021). Entretanto, como resultado da mineração, ocorre o surgimento de áreas degradadas, em que o uso desse solo para outras atividades a curto e médio prazo tornam-se inviáveis, devido o processo erosivo, retirada da camada fértil do solo e supressão da vegetação (Longo; Ribeiro; Melo, 2011; Yada et al., 2015; Borga; Campos, 2017; Barros et al., 2018). Além disso, o processo de reconstituição do perfil de solo e recuperação dos seus atributos químicos são lentos. Com isso, estratégias de recuperação de áreas degradadas, para diminuir o tempo de recuperação da fertilidade do solo, vêm ganhando destaque nos últimos anos.

Existem diferentes estratégias para recuperar áreas degradadas pela mineração, em que a escolha da melhor estratégia depende do destino da área, tecnologias disponíveis, grau de degradação, entre outras. Uma das estratégias que vem sendo utilizada com resultados promissores é o uso de mudas de vegetação nativa. Essa estratégia visa diminuir os impactos da 
erosão e recuperação da flora e processos ecológicos, em que é aconselhável o uso de espécies nativas, com sistema radicular profundo e rápida cobertura do solo (Neri et al., 2011; Silva; Campagna; Lipp-Nissinen, 2018). Além disso, o uso da vegetação propicia o aumento do aporte de biomassa essencial para a fertilidade do solo (Reis; Lima; Pauletto, 2014; Lima et al., 2015).

A melhoria dos teores dos nutrientes do solo é essencial para o pleno desenvolvimento da vegetação. Um dos indicadores de grande importância para avaliar a qualidade do solo é o teor da matéria orgânica. A matéria orgânica (MOS) é essencial para capacidade de troca de cátions, formação de agregados, melhorias nos teores de nutrientes no solo, entre outros fatores (Rangel-Vasconcelos; Kato; Vasconcelos, 2012; Brady; Weil, 2013). Teores adequados de fósforo e potássio contribuem para o desenvolvimento do sistema radicular, fotossíntese, atividade osmótica e diversos processos bioquímicos (Taiz et al., 2017).

Apesar do uso de vegetação nativa para recuperação de áreas submetidas à mineração ser promissora, poucas são as pesquisas que avaliam a evolução das características químicas do solo nessas áreas após o plantio na região amazônica. Com isso, a presente pesquisa busca contribuir com informações relacionadas à modificação da química do solo de áreas em processo de recuperação tendo como referência o solo com vegetação natural. Assim, o objetivo da presente pesquisa foi avaliar o efeito do uso da técnica de revegetação nos atributos químicos do solo (matéria orgânica do solo, $\mathrm{P}, \mathrm{K}, \mathrm{Ca}+\mathrm{Mg}, \mathrm{Al}$ ) em área sob a ação de extração de seixo na região amazônica.

\section{Metodologia}

A pesquisa experimental foi realizada em uma área de mineração de seixo no município de Capitão Poço - PA, entre as coordenadas geográficas $01^{\circ} 30^{\prime}$ e $02^{\circ} 35^{\prime} \mathrm{S}$ e $46^{\circ} 49^{\prime \prime}$ e $47^{\circ} 27^{\prime} \mathrm{O}$. O clima do município segundo a Classificação Climática de Köppen é o Ami, em que o clima é chuvoso, porém apresentando pequena estação seca (PACHECO; BASTOS, 2001). De acordo com as autoras, as temperaturas médias variam de $25,6^{\circ} \mathrm{C}$ no mês de julho a $26,9^{\circ} \mathrm{C}$ no mês de novembro, com precipitação média anual de $2.401,0 \mathrm{~mm}$.

No sítio experimental foram selecionadas duas áreas: uma área de 7,82 ha, constituída por um fragmento de floresta secundária (FS) e outra de 0,28 ha, resultante de uma área recém-explorada pela extração de seixo (Figura 1). Os depósitos de seixo em forma de lentes estão inseridos em Latossolo Vermelho-Amarelo com profundidades que variam entre 3 e 5 metros (Figura 2).

Para a execução dos tratamentos, inicialmente foi feita a terraplanagem do terreno manualmente, com ferramentas (enxada e pá) com transporte do material em carro de mão. Foram transportados cerca de 40 metros cúbicos de substrato (rejeito da mineração de seixo) que foram utilizados para cobrir irregularidades no terreno (depressões) para evitar o acúmulo de água e escoamento dos materiais que seriam utilizados para cobrir o substrato, nas parcelas. 
Figura 1 - Vista geral da localização das áreas do experimento. Floresta secundária, delimitada por linha em azul (A) e da distribuição das subparcelas do experimento de recuperação de área degradada, na área de mineração de seixo (B), no município de Capitão Poço, Pará.
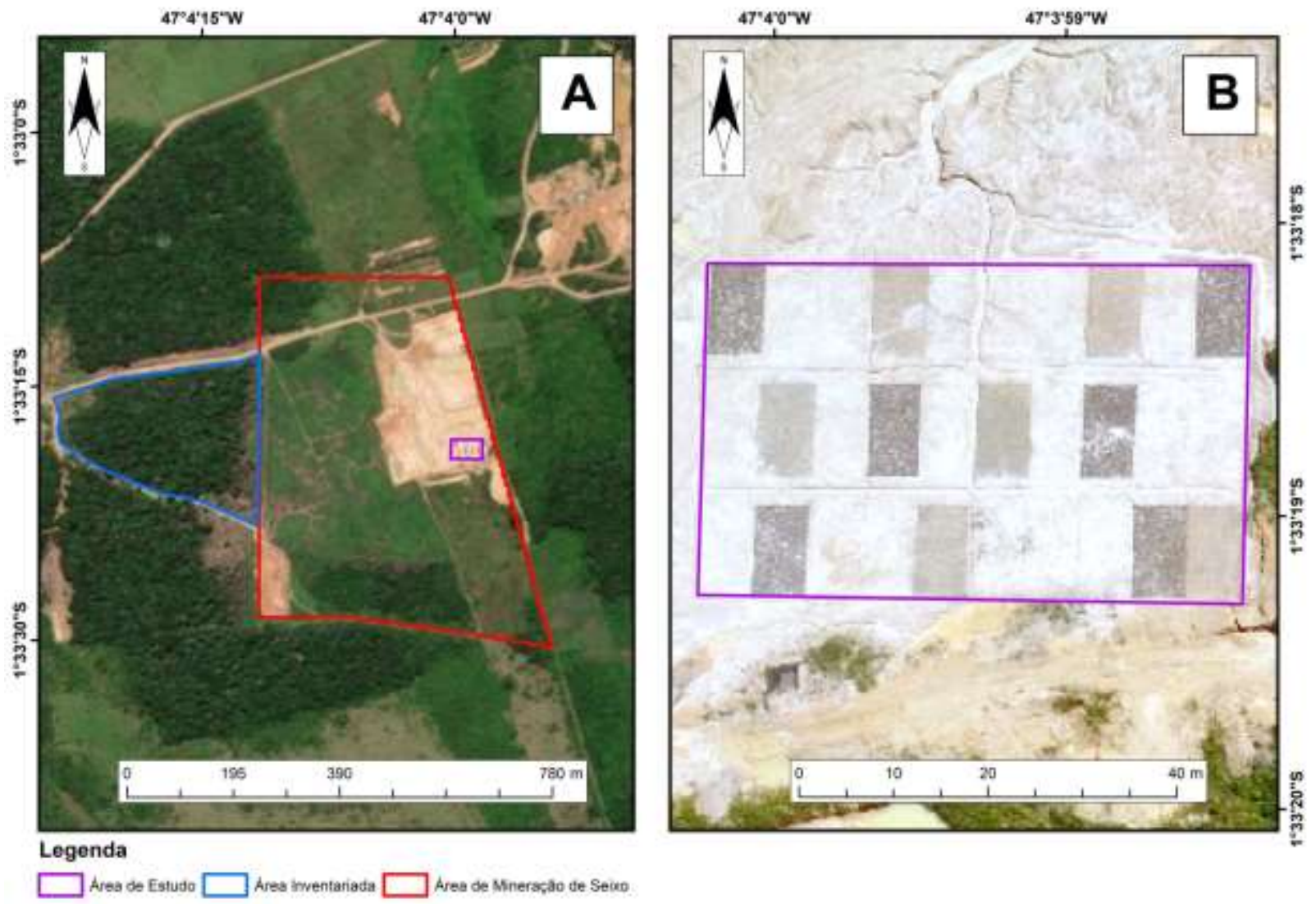

Fonte: José Antônio Lima Rocha Junior

Figura 2 - Vista geral do depósito de seixo em forma de lente na área de mineração de seixo à céu aberto, no município de Capitão Poço, Pará.

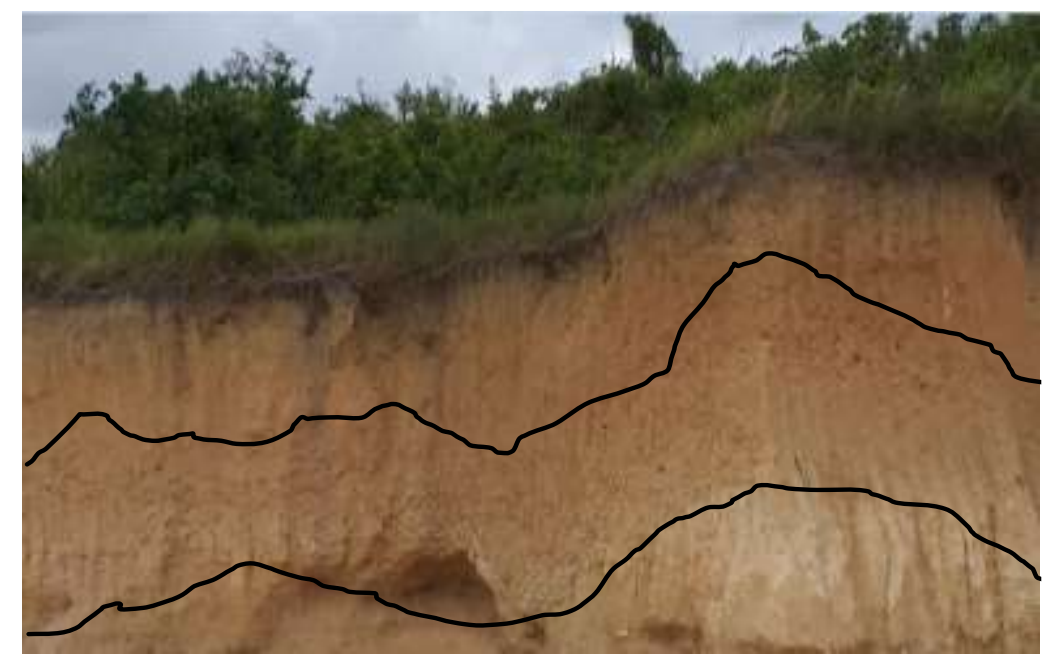

Fonte: Autores.

Do horizonte A (material orgânico - topsoil) da superfície do solo, das adjacências da área minerada, foram retirados cerca de 10,5 metros cúbicos e distribuídos na superfície de algumas subparcelas. Foram utilizados $135 \mathrm{~kg}$ de calcário 
dolomítico, para correção do $\mathrm{pH}$, e colocados sobre o substrato das parcelas. Da floresta secundária foram retirados 66 sacos de serapilheira (cada um com cerca de $40 \mathrm{Kg}$ ) e colocada sobre as parcelas.

$\mathrm{O}$ experimento foi conduzido em uma área recém-explorada pela extração de seixo. Foi conduzido de acordo com o "método de revegetação", utilizando-se espécies vegetais presentes na região. Mudas das seguintes espécies foram produzidas: Embaúba (Cecropia distachya Huber), Ingazeiro (Inga heterophylla Willd), Acácia (Cassia sp.), Tamanqueira (Zanthoxylum rhoifolium Lam), Envira-preta (Guatteria poeppigiana Mart.), Acacia-australiana (Acacia mangium Willd) e Envirão (Guatteria vilosíssima A. St.-Flil). A produção de mudas ocorreu em ambiente protegido usando-se saco de polietileno com dimensões de $10 \mathrm{~cm} \times 15 \mathrm{~cm}$, preenchidos com um substrato constituído de solo (Latossolo Amarelo textura média) + serragem fina + cama aviária na proporção de 2:1:1. A implantação do experimento ocorreu em maio de 2018 (SAUMA FILHO et al., 2020; 2021).

O delineamento experimental usado foi em blocos ao acaso, em parcelas subdivididas, com os tratamentos distribuídos em três blocos. As parcelas foram constituídas de dois tratamentos - calagem + escarificação (CC) e sem calagem e sem escarificação (SC). As subparcelas foram compostas de cinco tratamentos: 1) plantio de mudas de sete espécies $+500 \mathrm{~kg}$ de serrapilheira (camada com $5 \mathrm{~cm}$ de espessura); 2) plantio de mudas de sete espécies $+50 \mathrm{~g} / \mathrm{planta}$ de NPK da formulação 20-10-20 + $200 \mathrm{~g} /$ planta de cama aviária; 3) plantio de mudas de sete espécies + 50 g/planta de NPK da formulação 20-10-20 + $200 \mathrm{~g} / \mathrm{planta}$ de cama aviária + plantio de duas linhas de feijão-caupi entre as linhas das sete espécies; 4) plantio de mudas de sete espécies + $50 \mathrm{~g} /$ planta de NPK da formulação $20-10-20+200 \mathrm{~g} /$ planta de cama aviária $+500 \mathrm{~kg}$ de topsoil e 5) testemunha (regeneração natural). Em cada subparcela foram plantadas quatro mudas de cada espécie, totalizando 28 plantas por subparcela, distribuídas em arranjo espacial quadrangular de $1,5 \mathrm{~m} \mathrm{x} \mathrm{1,5} \mathrm{m.} \mathrm{Cada} \mathrm{parcela} \mathrm{e} \mathrm{subparcela} \mathrm{medem} 300 \mathrm{~m}^{2}$ (30m x 10m) e $60 \mathrm{~m}^{2}(6 \mathrm{~m} \times 10 \mathrm{~m})$, respectivamente e, o bloco $600 \mathrm{~m}^{2}(60 \mathrm{~m} \times 10 \mathrm{~m})$.

Logo após o plantio das mudas foi realizado uma proteção parcial, visando reduzir a intensidade de radiação solar incidente e a velocidade do vento na área do experimento, utilizando ramos de plantas nativas que vegetam próximo da área do experimento, durante 15 dias. O controle de plantas daninhas foi realizado quando necessário, inicialmente por meio de mondas e, depois, com roçagens, sempre na área de projeção da copa das plantas, deixando-se o material retirado nessa área. Também foi realizado o tutoramento de algumas plantas sempre que necessário. Durante o segundo semestre de 2018, realizaram-se molhamentos das plantas a cada três dias utilizando de 5 a $10 \mathrm{~L}$ de água por planta, respectivamente para as menos e mais desenvolvidas.

Para as avaliações da química do solo, foram retiradas duas amostras simples por amostra composta, a profundidade de 0 a $10 \mathrm{~cm}$ e 10 a $20 \mathrm{~cm}$, em cada subparcela, utilizando-se cavadeira articulada, pá reta, enxada e balde. As amostras simples de cada subparcela foram colocadas em balde limpo, misturadas e, em seguida, retiraram-se uma amostra de cerca de $500 \mathrm{~g}$ de solo e colocou-se em um saco de polietileno devidamente etiquetado com o número da subparcela. As amostras de solos foram enviadas para o Laboratório de Solos da Embrapa Amazônia Oriental, para determinação das seguintes características químicas do solo: MOS, pelo método de Walkley; Black (1934); P, por extração com solução Mehlich 1, e determinação por espectrofotometria; K e Na, extração com solução Mehlich 1, e determinação por fotometria de chama; Al, $\mathrm{Ca}$ e $(\mathrm{Ca}+\mathrm{Mg})$, por espectrometria de absorção atômica (EMBRAPA, 2017).

Os dados gerais obtidos nas diferentes etapas deste estudo foram submetidos à análise de variância, e as médias, quando apresentaram efeitos significativos, ao teste de Tukey $(\mathrm{p}<0,05)$, utilizando software BioEstat (Barbosa; Maldonado Júnior, 2015). Gráficos foram realizados por meio do Microsoft Office Excel versão 2003. 


\section{Resultados e Discussão}

Nas Tabelas 1, 2 e 3 estão representados os valores médios das características químicas do solo construído, após extração de seixo, a céu aberto, referentes à matéria orgânica do solo (MOS), fósforo (P) e potássio (K). Nas Figuras 3 e 4, encontram-se os teores médios de MOS, P e K, obtidos no solo sob floresta secundária, "área de referência", nas camadas de 0 a $10 \mathrm{~cm}$ e 10 a $20 \mathrm{~cm}$, após oito e dezesseis meses e, ainda, na serapilheira e topsoil, usados como constituintes de alguns tratamentos dessa pesquisa.

Tabela 1 - Valores médios de matéria orgânica do solo (MOS), fósforo (P) e potássio (K), do solo construído após extração de seixo, a céu aberto, em função da profundidade do solo (Ps), após oito e dezesseis meses da implantação do experimento ${ }^{1}$.

\begin{tabular}{lllllll}
\hline Ps $(\mathrm{cm})$ & \multicolumn{2}{c}{ MOS $\left(\mathrm{g} \mathrm{kg}^{-1}\right)$} & \multicolumn{2}{c}{$\mathrm{P}\left(\mathrm{mg} \mathrm{dm}^{-3}\right)$} & \multicolumn{2}{c}{$\mathrm{K}\left(\mathrm{mg} \mathrm{dm}^{-3}\right)$} \\
\cline { 2 - 7 } & 8 meses & 16 meses & 8 meses & 16 meses & 8 meses & 16 meses \\
\hline $0-10$ & $3,43 \mathrm{a}$ & $3,38 \mathrm{a}$ & $2,17 \mathrm{a}$ & $2,33 \mathrm{a}$ & $12,20 \mathrm{a}$ & $7,80 \mathrm{a}$ \\
$10-20$ & $2,56 \mathrm{~b}$ & $1,69 \mathrm{~b}$ & $1,03 \mathrm{~b}$ & $1,48 \mathrm{~b}$ & $6,50 \mathrm{~b}$ & $5,42 \mathrm{~b}$ \\
\hline $\mathrm{CV}(\%)$ & 21,09 & 20,49 & 26,48 & 20,72 & 16,64 & 20,31 \\
\hline
\end{tabular}

${ }^{1}$ Em cada coluna, letras minúsculas diferentes diferem entre si, pelo teste de Tukey $(\mathrm{p}<0,05)$. Fonte: Autores.

Com relação aos teores médios de MOS, P e K, apresentados na Tabela 1, constataram-se reduções significativas ( <0,05) no solo construído, na camada de 10 a $20 \mathrm{~cm}$ de profundidade (Ps), nos dois períodos de avaliação; essas reduções em relação a camada de 0 a 10 cm, variaram de 25,36 e 50,00\%, 52,53 e 36,48\% e, 46,72 e 30,51\%, respectivamente para MOS, P e K, após oito e dezesseis meses, respectivamente. No solo construído, os maiores teores foram observados após oito meses para $\operatorname{MOS}\left(3,43 \mathrm{~g} \mathrm{~kg}^{-1}\right)$ e $\mathrm{K}\left(12,20 \mathrm{mg} \mathrm{dm}^{-3}\right)$ e aos dezesseis meses para $\mathrm{P}\left(2,33 \mathrm{mg} \mathrm{dm}^{-3}\right)$, todos na camada de 0 a $10 \mathrm{~cm}$ de profundidade (Tabela 1). Em geral, os teores de MOS, P e K, no solo construído, são inferiores se comparados com os valores obtidos na área de referência "floresta secundária" (Tabela 1 e Figuras 3 e 4), com exceção do teor de P, nas camadas de 0 a 10 e 10 a $20 \mathrm{~cm}$, após oito meses. Comparativamente, esses teores, em relação aos obtidos no solo da área de referência "floresta secundária" foram menores, em média, 83,35 e 87,63\%; 83,35 e 92,78\% para MOS e, maiores, em média 38,25 e 191,26\%; 22,63 e 13,85\% para P e, menores, em média, 63,58 e 77,19\%; 57,38 e 68,67\% para K, nas camadas de 0 a $10 \mathrm{~cm}$ e 10 a $20 \mathrm{~cm}$ de profundidade, aos oito e dezesseis meses, respectivamente. Yada et al. (2015) ao analisarem os atributos químicos de uma área degradada por extração de estanho em fase de recuperação por leguminosas, observaram valores de MO significativamente inferiores à observada em área de mata, fato relacionado ao processo lento de formação da matéria orgânica e que os tratamentos aplicados não foram suficientes para recompor a MOS perdida. Por outro lado, os autores observaram valores de $\mathrm{K}$ estatisticamente iguais dos tratamentos com a área de mata. Longo; Ribeiro e Melo (2011) também não verificaram diferença significativa entre diferentes coberturas vegetais e solo nu em área degradada por mineração da Amazônia. Os autores afirmaram que 15 meses decorridos não foram suficientes para mudanças na MOS, situação observada na presente pesquisa. 
Figura 3 - Teores médios de matéria orgânica (MOS) no solo sob floresta secundária "área de referência" (A) e, na serapilheira e topsoil (B) usados como componentes de tratamentos do solo construído na área de mineração de seixo, no município de Capitão Poço, PA.

A

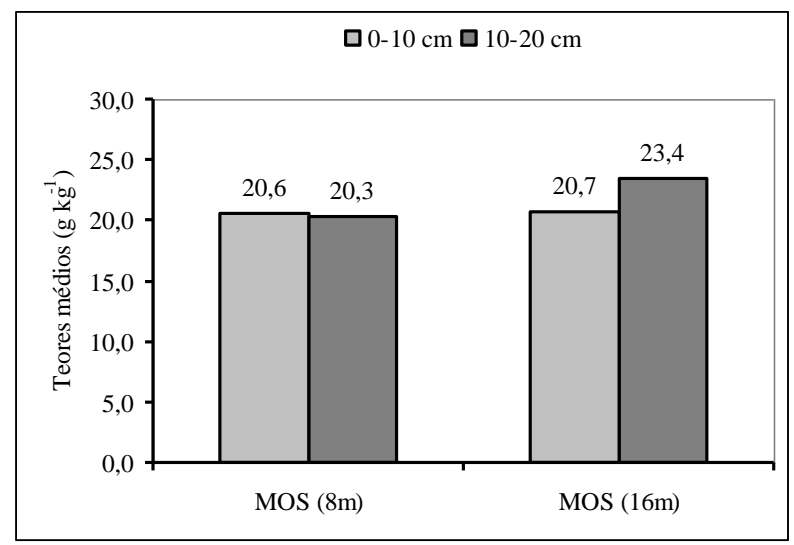

B

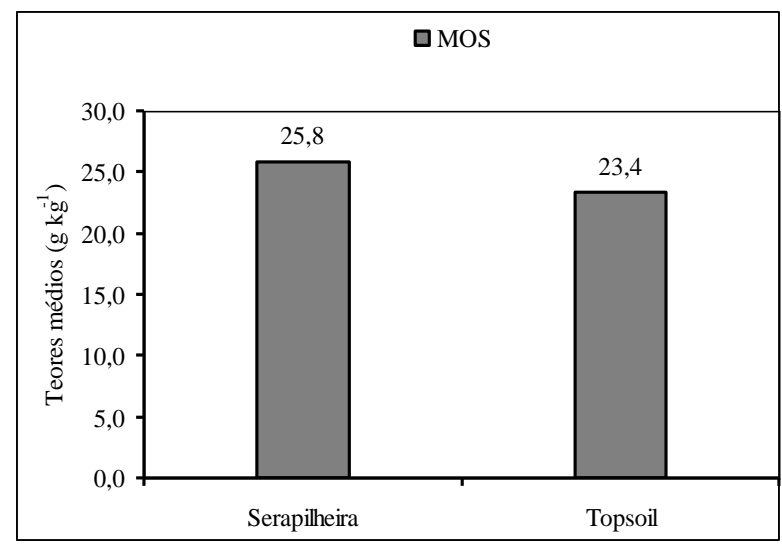

Fonte: Autores.

Figura 4 - Teores médios de fósforo $(P)$ e potássio $(K)$ no solo sob floresta secundária "área de referência" (A) e, na serapilheira e topsoil (B) usados como componentes de tratamentos do solo construído na área de mineração de seixo, no município de Capitão Poço, PA.

A

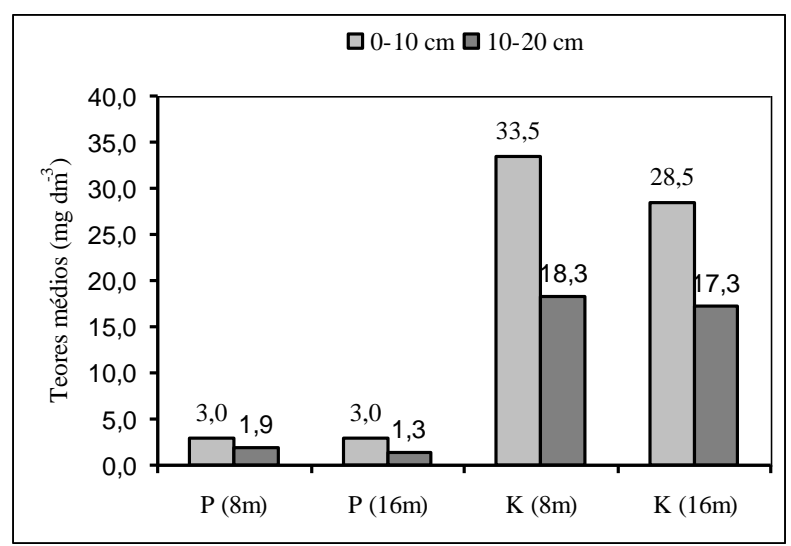

B

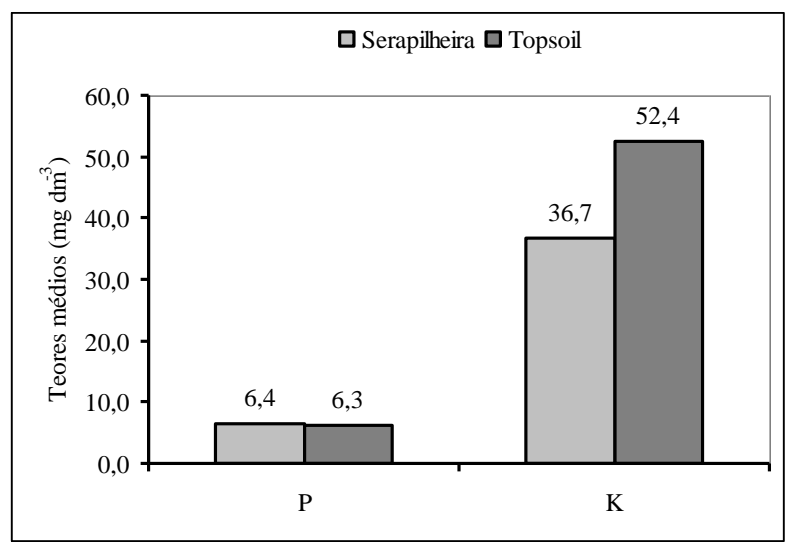

Fonte: Autores.

$\mathrm{Na}$ Tabela 2 estão representados os valores médios dos teores de matéria orgânica do solo (MOS), fósforo (P) e potássio $(\mathrm{K})$, obtidos pelo desdobramento da interação métodos de recuperação (M) x profundidade do solo (Ps). Os teores médios de MOS, estatisticamente ( $\mathrm{p}<0,05)$, foram maiores nos tratamentos M4 e M1 (5,52 e 4,06 $\mathrm{g} \mathrm{kg}^{-1} \mathrm{de}^{\mathrm{MOS}}$, respectivamente), na Ps de 0 a $10 \mathrm{~cm}$ (Tabela 2). $\mathrm{O}$ maior teor de $\mathrm{P}$ foi obtido no tratamento $\mathrm{M} 4\left(3,00 \mathrm{mg} \mathrm{dm}^{-3}\right)$, não se diferenciando estatisticamente do tratamento M3 $\left(2,67 \mathrm{mg} \mathrm{dm}^{-3}\right)$, ambos dentro do tratamento de Ps de 0 a $10 \mathrm{~cm}$; na Ps de 10 a $20 \mathrm{~cm}$; não se detectou efeito significativo entre os tratamentos $\mathrm{M}$ e, os teores de $\mathrm{P}$, variaram entre 1,0 a $1,17 \mathrm{mg} \mathrm{dm}^{-3}$ (Tabela 2). Dentro de cada tratamento M, constataram-se reduções significativas nos teores de P, alcançando 66,67 e 62,55\% para os tratamentos M4 e M3, respectivamente, na Ps de 10 a $20 \mathrm{~cm}$. 
O comportamento do potássio (K) no solo construído na área do experimento está expresso na Tabela 2. Observam-se efeitos significativos para a interação M x Ps (p<0,05). Assim sendo, após 8 meses, na Ps de 0 a 10 cm, o maior teor de K foi detectado no tratamento M4 (17,00 $\left.\mathrm{mg} \mathrm{dm}^{-3}\right)$, não se diferenciando significativamente dos tratamentos $\mathrm{M} 1\left(12,00 \mathrm{mg} \mathrm{dm}^{-3}\right) \mathrm{e}$ M3 (11,67 $\mathrm{mg} \mathrm{dm}^{-3}$ ); após 16 meses, os teores de $\mathrm{K}$ não foram influenciados significativamente. Dentro de cada tratamento M, constataram-se os maiores teores desse atributo nos tratamentos M1 e M4, na presença do tratamento Ps de 0 a $10 \mathrm{~cm}$ em relação tratamento Ps de 10 a $20 \mathrm{~cm}$.

Tabela 2 - Valores médios para o desdobramento da interação dupla significativa entre método de recuperação (M) x profundidade do solo (Ps), em relação à matéria orgânica do solo (MOS), fósforo (P) e potássio (K), após oito meses da implantação do experimento ${ }^{1}$.

\begin{tabular}{|c|c|c|c|c|c|c|}
\hline \multirow[t]{3}{*}{$\mathrm{M}^{2}$} & \multicolumn{6}{|c|}{ Ps, em cm } \\
\hline & \multicolumn{2}{|c|}{$\operatorname{MOS}\left(\mathrm{g} \mathrm{kg}^{-1}\right)$} & \multicolumn{2}{|c|}{$\mathrm{P}\left(\mathrm{mg} \mathrm{dm}^{-3}\right)$} & \multicolumn{2}{|c|}{$\mathrm{K}\left(\mathrm{mg} \mathrm{dm}^{-3}\right)$} \\
\hline & $0-10$ & $10-20$ & $0-10$ & $10-20$ & $0-10$ & $10-20$ \\
\hline M1 & $4,06 \mathrm{abA}$ & $2,79 \mathrm{aA}$ & $1,83 \mathrm{bA}$ & $1,17 \mathrm{aA}$ & $12,00 \mathrm{abA}$ & $8,83 \mathrm{aB}$ \\
\hline M2 & $2,12 \mathrm{bA}$ & $2,13 \mathrm{aA}$ & $1,33 \mathrm{cA}$ & $1,00 \mathrm{aA}$ & $9,17 \mathrm{bA}$ & $5,17 \mathrm{aA}$ \\
\hline M3 & $2,18 \mathrm{bA}$ & $2,38 \mathrm{aA}$ & $2,67 \mathrm{abA}$ & $1,00 \mathrm{aB}$ & $11,67 \mathrm{bA}$ & $7,50 \mathrm{aA}$ \\
\hline M4 & $5,52 \mathrm{aA}$ & $2,45 \mathrm{aB}$ & $3,00 \mathrm{aA}$ & $1,00 \mathrm{aB}$ & $17,00 \mathrm{aA}$ & 7,33 aB \\
\hline M5 & $2,28 \mathrm{bA}$ & $2,24 \mathrm{aA}$ & $1,00 \mathrm{cA}$ & $1,00 \mathrm{aA}$ & $4,17 \mathrm{cA}$ & $3,67 \mathrm{aA}$ \\
\hline $\mathrm{CV}_{\mathrm{M}}(\%)$ & \multicolumn{2}{|c|}{22,32} & \multicolumn{2}{|c|}{21,05} & \multicolumn{2}{|c|}{17,56} \\
\hline $\mathrm{CV}_{\mathrm{Ps}}(\%)$ & \multicolumn{2}{|c|}{21,09} & \multicolumn{2}{|c|}{26,48} & \multicolumn{2}{|c|}{16,64} \\
\hline
\end{tabular}

${ }^{1}$ Letras minúsculas comparam a correção e escarificação superficial dentro de cada método de recuperação de áreas degradadas e as maiúsculas comparam os métodos de recuperação de áreas degradadas dentro de cada correção e escarificação superficial, pelo teste de Tukey $(\mathrm{p}<0,05)$.

${ }^{2} \mathrm{CC}=$ com correção e escarificação superficial do solo e $\mathrm{SC}=$ sem correção e sem escarificação do solo.

${ }^{3} \mathrm{M} 1=$ plantio de mudas + cobertura superficial da área da parcela com $500 \mathrm{~kg}$ de serapilheira, $\mathrm{M} 2=$ plantio de mudas $+50 \mathrm{~g}$ planta-1 de NPK +200 g planta $^{-1}$ de cama aviária, M3 = plantio de mudas $+50 \mathrm{~g} \mathrm{planta}^{-1}$ de NPK $+200 \mathrm{~g} \mathrm{planta}^{-1}$ de cama aviária + feijão-caupi, nas entrelinhas, $\mathrm{M} 4=$ plantio de mudas $+50 \mathrm{~g}_{\text {planta }}{ }^{-1}$ de NPK $+200 \mathrm{~g}$ planta $^{-1}$ de cama aviária + cobertura superficial da área da subparcela com $500 \mathrm{~kg}$ de topsoil e M5 = com ou sem calagem e escarificação superficial.

Fonte: Autores.

Analisando os dados apresentados nas Tabelas 1 e 2, constata-se que a interação significativa dos fatores $M$ e Ps resultaram em efeitos sinérgicos nos atributos químicos do solo construído, principalmente nos tratamentos M4 e M1 para C, MOS e K e, para o P nos tratamentos M4 e M3 (Tabela 2). O aumento observado nesses atributos químicos do solo construído, principalmente nos tratamentos M1 e M4, pode ser explicado, em parte à aplicação superficial da serapilheira e do topsoil. Considera-se que, a serapilheira é particularmente importante por atuar na superfície do solo como um aporte de entrada de biomassa que, posteriormente é decomposta e contribui na disponibilidade de nutrientes. De acordo com Gonçalves, Martins e Correia (2020), o topsoil é usado como fonte de matéria orgânica, nutrientes e sementes, podendo favorecer o restabelecimento das condições químicas do solo da área minerada.

Os teores médios de matéria orgânica do solo (MOS), após dezesseis meses da implantação do experimento, obtidos em função do desdobramento da interação dupla significativa CE x M, estão representados na Tabela 3. Os teores médios da MOS são significativamente menores nos tratamentos M2 (1,46 $\left.\mathrm{g} \mathrm{kg}^{-1}\right)$ e M4 (2,27 $\left.\mathrm{g} \mathrm{kg}^{-1}\right)$ no tratamento SC, em relação aos respectivos tratamentos $\mathrm{CC}$, esses teores foram equivalentes as reduções de 59,56 e 60,66\%, respectivamente, em relação aos seus tratamentos correspondentes no tratamento $\mathrm{CC}\left(\mathrm{M} 2=3,61 \mathrm{~g} \mathrm{~kg}^{-1}\right.$ e M4 $\left.=5,77 \mathrm{~g} \mathrm{~kg}^{-1}\right)$. Dentro dos tratamentos CE, os teores médios da MOS apresentaram efeitos significativos $(\mathrm{p}<0,05)$ e obedeceram a seguinte ordem decrescente CC: M4 = M2 > M1 = M3 > M5 e SC: M1 = M4 > M3 = M2 > M5 (Tabela 3). Da mesma forma, quando se comparam as Tabelas 1 e 3 , observam-se efeitos sinérgicos para os teores de MOS, em relação ao fator Ps (Tabela 3), ou seja, ocorreu incremento nos teores à semelhança do observado para a interação M x Ps (Tabelas 1 e 2). 
Tabela 3 - Valores médios para o desdobramento da interação dupla significativa entre calagem e escarificação superficial (CE) x métodos de recuperação (M), em relação a matéria orgânica do solo (MOS), após dezesseis meses da implantação do experimento ${ }^{1}$.

\begin{tabular}{|c|c|c|c|c|}
\hline \multirow[t]{3}{*}{$\mathrm{CE}^{2}$} & \multicolumn{4}{|c|}{$\mathrm{M}^{3}$} \\
\hline & \multicolumn{4}{|c|}{$\operatorname{MOS}\left(\mathrm{g} \mathrm{kg}^{-1}\right)$} \\
\hline & M2 & M3 & M4 & M5 \\
\hline $\mathrm{CC}$ & $3,61 \mathrm{aAB}$ & $2,92 \mathrm{aB}$ & $5,77 \mathrm{aA}$ & $1,87 \mathrm{aC}$ \\
\hline $\mathrm{SC}$ & $2,36 \mathrm{aA}$ & $1,55 \mathrm{aB}$ & $2,27 \mathrm{bA}$ & $0,62 \mathrm{aC}$ \\
\hline $\mathrm{CV}_{\mathrm{CE}}(\%)$ & \multicolumn{4}{|c|}{32,10} \\
\hline $\mathrm{CV}_{\mathrm{M}}(\%)$ & \multicolumn{4}{|c|}{20,49} \\
\hline \multicolumn{5}{|c|}{ 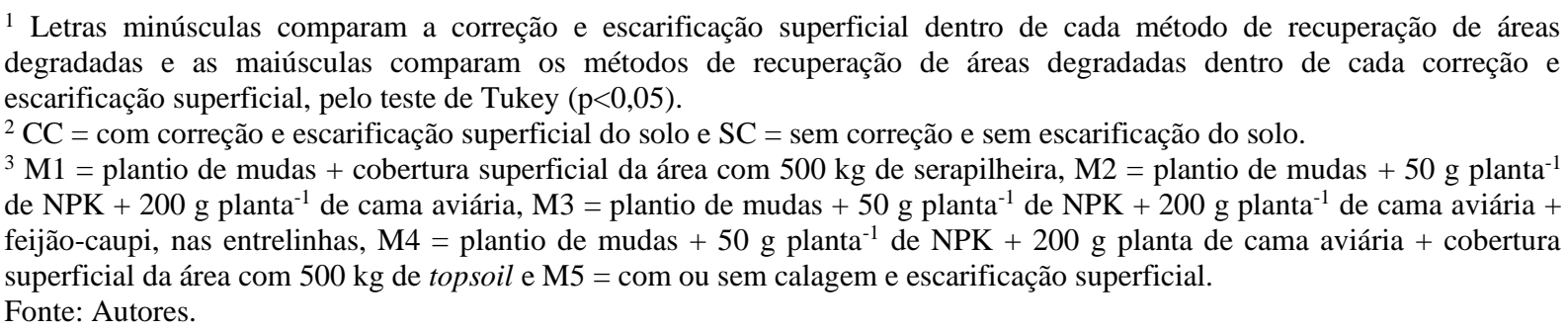 } \\
\hline
\end{tabular}

Nas Tabelas 4, 5 e 6 estão representados os efeitos do fator método de recuperação usado "plantio de mudas" e das interações duplas significativas $(\mathrm{p}<0,05) \mathrm{M}$ x CE e CE x Ps obtidos para teores médios de $\mathrm{Na}, \mathrm{Al}, \mathrm{Ca}$ e $\mathrm{Ca}+\mathrm{Mg}$. Na Figura 5 estão representados os teores médios desses atribuídos químicos, determinados na camada superficial do solo sob floresta secundária, "área de referência", onde foram coletadas a serapilheira e o topsoil, usadas em alguns tratamentos desta pesquisa. 
Figura 5 - Teores médios de sódio $(\mathrm{Na})$, alumínio $(\mathrm{Al})$, cálcio $(\mathrm{Ca})$ e cálcio $(\mathrm{Ca})$ + magnésio $(\mathrm{Mg})$ no solo sob floresta secundária "área de referência" (A, B) e, na serapilheira e topsoil (C, D) usados como componentes de tratamentos do solo construído na área de mineração de seixo, no município de Capitão Poço, PA.

A

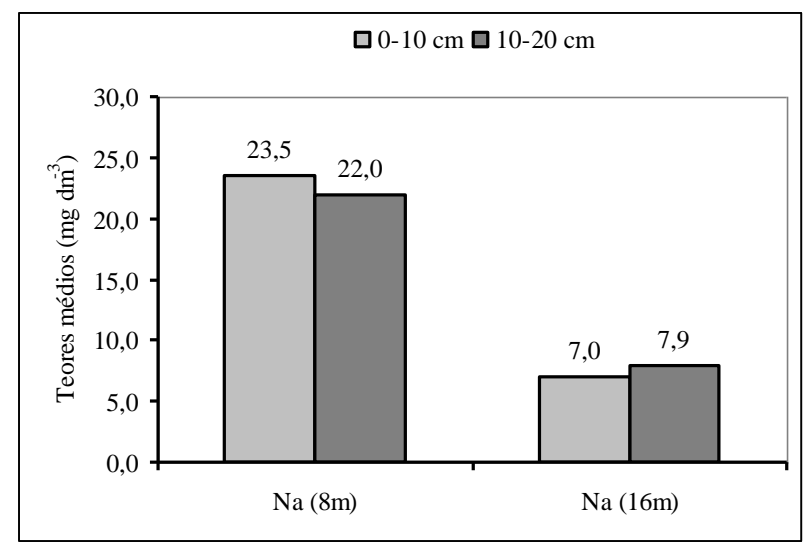

C

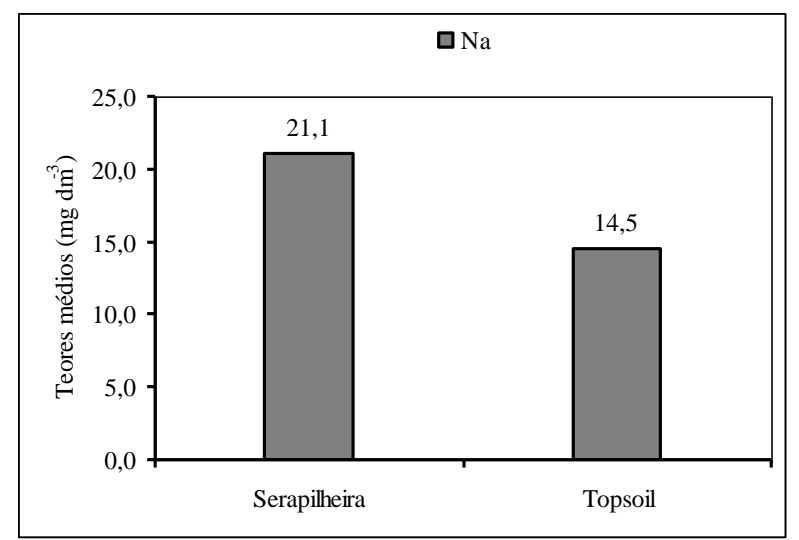

B

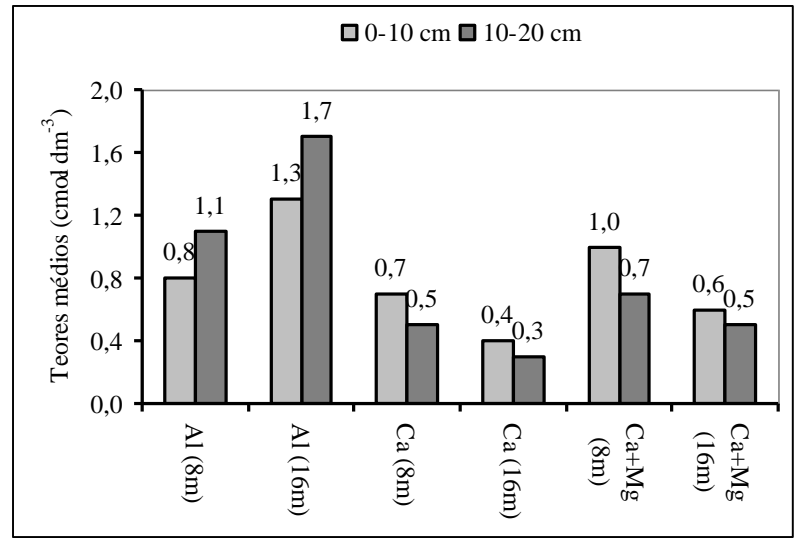

D

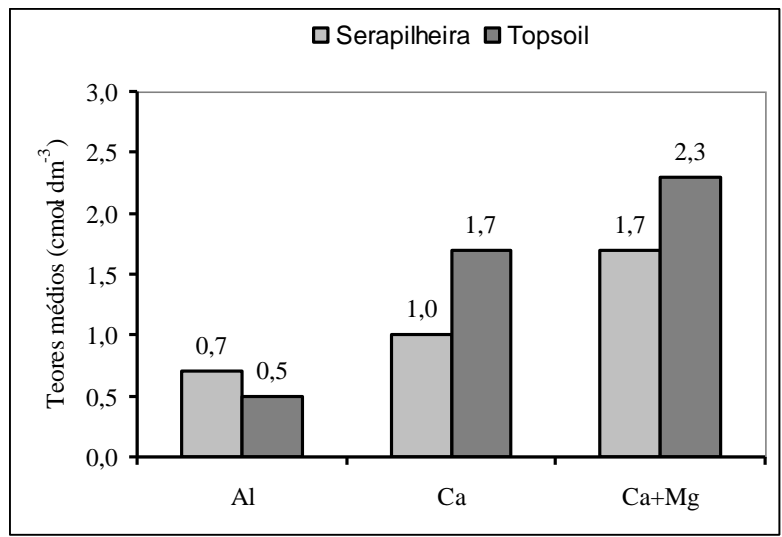

Fonte: Autores.

Com relação ao $\mathrm{Na}$, o maior teor desse elemento foi constatado no $\mathrm{M} 3\left(6,33 \mathrm{mg} \mathrm{dm}^{-3}\right)$, sem se diferenciar estatisticamente $(\mathrm{p}<0,05)$ de M1 $\left(5,17 \mathrm{mg} \mathrm{dm}^{-3}\right)$, M4 $\left(5,08 \mathrm{mg} \mathrm{dm}^{-3}\right)$ e M2 $\left(4,83 \mathrm{mg} \mathrm{dm}^{-3}\right)$, após oito meses. Aos dezesseis meses, os teores de Na aumentaram nos tratamentos M3 (5,81 $\left.\mathrm{mg} \mathrm{dm}^{-3}\right)$ e M2 $\left(5,41 \mathrm{mg} \mathrm{dm}^{-3}\right)$, mas não se diferenciaram do tratamento M1 (5,13 $\mathrm{mg} \mathrm{dm}^{-3}$ ) (Tabela 4). Os teores de Al e Ca não foram influenciados significativamente, após oito meses, no solo construído e, aos dezesseis meses, houve redução no tratamento M5 $\left(0,57 \mathrm{cmol}_{\mathrm{c}} \mathrm{dm}^{-3}\right)$ para o $\mathrm{Al}$ e, para o Ca, nos tratamentos M2 $\left(0,13 \mathrm{cmol}_{\mathrm{c}} \mathrm{dm}^{-3}\right), \mathrm{M} 3\left(0,13 \mathrm{cmol}_{\mathrm{c}} \mathrm{dm}^{-3}\right)$ e M5 $\left(0,19 \mathrm{cmol}_{\mathrm{c}} \mathrm{dm}^{-3}\right)$ (Tabela 4). Os maiores teores de Ca+Mg foram constatados nos tratamentos M1, M3, M4 e M5, após oito meses e, após dezesseis meses não se detectou efeitos significativos entre os tratamentos. Os teores médios de $\mathrm{Ca}+\mathrm{Mg}$ variaram entre $0,22 \mathrm{e} 0,50 \mathrm{cmol}_{\mathrm{c}} \mathrm{dm}^{-3}$, nos tratamentos $\mathrm{M} 2 \mathrm{e}$ M1, respectivamente (Tabela 4). É importante ressaltar os baixos teores de Al nos solos construídos, condição essencial para o desenvolvimento da vegetação, tendo em vista que altos teores de Al inibe o crescimento do sistema radicular e, posteriormente, da parte aérea (Hartwig et al., 2007; Taiz et al., 2017). 
Tabela 4 - Valores médios para sódio $(\mathrm{Na})$, alumínio $(\mathrm{Al})$, cálcio $(\mathrm{Ca})$ e cálcio+magnésio $(\mathrm{Ca}+\mathrm{Mg})$, em função do fator métodos de recuperação de áreas degradadas (M), após oito e dezesseis meses de implantação do experimento ${ }^{1}$.

\begin{tabular}{llllllllc}
\hline $\mathrm{M}^{2}$ & \multicolumn{2}{l}{$\mathrm{Na}\left(\mathrm{mg} \mathrm{dm}^{-3}\right)$} & \multicolumn{2}{l}{$\mathrm{Al}\left(\mathrm{cmol}_{\mathrm{c}} \mathrm{dm}^{-3}\right)$} & \multicolumn{2}{c}{$\mathrm{Ca}\left(\mathrm{cmol}_{\mathrm{c}} \mathrm{dm}^{-3}\right)$} & \multicolumn{2}{c}{$\left.\mathrm{Ca}+\mathrm{cmol}_{\mathrm{c}} \mathrm{dm}^{-3}\right)$} \\
\cline { 2 - 8 } & 8 meses & 16 meses & 8 meses & 16 meses & 8 meses & 16 meses & 8 meses & 16 meses \\
\hline M1 & $5,17 \mathrm{ab}$ & $5,13 \mathrm{ab}$ & $0,52 \mathrm{a}$ & $0,62 \mathrm{a}$ & $0,49 \mathrm{a}$ & $0,34 \mathrm{a}$ & $0,73 \mathrm{a}$ & $0,50 \mathrm{a}$ \\
M2 & $4,83 \mathrm{ab}$ & $5,41 \mathrm{a}$ & $0,63 \mathrm{a}$ & $0,63 \mathrm{a}$ & $0,21 \mathrm{a}$ & $0,13 \mathrm{~b}$ & $0,33 \mathrm{~b}$ & $0,22 \mathrm{a}$ \\
M3 & $6,33 \mathrm{a}$ & $5,81 \mathrm{a}$ & $0,53 \mathrm{a}$ & $0,77 \mathrm{a}$ & $0,24 \mathrm{a}$ & $0,13 \mathrm{~b}$ & $0,39 \mathrm{a}$ & $0,23 \mathrm{a}$ \\
M4 & $5,08 \mathrm{ab}$ & $3,57 \mathrm{bc}$ & $0,53 \mathrm{a}$ & $0,78 \mathrm{a}$ & $0,30 \mathrm{a}$ & $0,22 \mathrm{ab}$ & $0,46 \mathrm{a}$ & $0,28 \mathrm{a}$ \\
M5 & $3,67 \mathrm{~b}$ & $3,16 \mathrm{c}$ & $0,48 \mathrm{a}$ & $0,57 \mathrm{~b}$ & $0,28 \mathrm{a}$ & $0,19 \mathrm{~b}$ & $0,42 \mathrm{a}$ & $0,33 \mathrm{a}$ \\
\hline CV (\%) & 29,20 & 28,17 & 29,49 & 25,65 & 22,19 & 29,05 & 20,58 & 20,45 \\
\hline
\end{tabular}

\footnotetext{
${ }^{1}$ Em cada coluna, letras minúsculas iguais, não diferem entre si, ao nível de 0,05 de probabilidade, pelo teste de Tukey $(\mathrm{p}<0,05)$.

${ }^{2} \mathrm{M} 1=$ plantio de mudas + cobertura superficial da área com $500 \mathrm{~kg}$ de serapilheira, M2 = plantio de mudas $+50 \mathrm{~g} \mathrm{planta}^{-1}$ de NPK +200 g planta $^{-1}$ de cama aviária, M3 = plantio de mudas $+50 \mathrm{~g} \mathrm{planta}^{-1}$ de NPK $+200 \mathrm{~g} \mathrm{planta}^{-1}$ de cama aviária + feijão-caupi, nas entrelinhas, $\mathrm{M} 4=$ plantio de mudas $+50 \mathrm{~g}_{\text {planta }}^{-1} \mathrm{de} \mathrm{NPK}+200 \mathrm{~g}$ planta de cama aviária + cobertura superficial da área com $500 \mathrm{~kg}$ de topsoil e M5 = com ou sem calagem e escarificação superficial.

Fonte: Autores.
}

$\mathrm{Na}$ Tabela 5 estão representados os teores médios de $\mathrm{Na}$ obtidos por meio do desdobramento da interação $\mathrm{M}$ x CE, após oito e dezesseis meses de implantação do experimento. Após oito meses, observam-se em SC que, os teores médios de $\mathrm{Na}$, nos tratamentos M1 (3,67 $\left.\mathrm{mg} \mathrm{dm}^{-3}\right)$ e M5 (2,33 $\left.\mathrm{mg} \mathrm{dm}^{-3}\right)$ foram reduzidos. Após dezesseis meses, observam-se nos tratamentos CC e SC que, os teores médios de Na foram reduzidos nos tratamentos M4 (3,23 mg dm $\left.\mathrm{m}^{-3}\right)$ e M5 (3,65 mg dm $\left.\mathrm{m}^{-3}\right)$ e, em M2 (3,43 $\left.\mathrm{mg} \mathrm{dm}^{-3}\right)$ e M5 (2,67 $\left.\mathrm{mg} \mathrm{dm}^{-3}\right)$, respectivamente (Tabela 5). Com esses resultados observa-se o efeito positivo do uso da revegetação e calagem na redução do $\mathrm{Na}$, visto que, em geral, esse elemento interage de forma benéfica com diferentes grupos de plantas (C3 e C4), em que quando presente em pequenas quantidades no solo estimula o crescimento vegetal. Porém, em alta concentração no solo possui efeito salino, impedindo a absorção de água do solo pelas raízes, resultando prejuízos no crescimento e desenvolvimento vegetal (TAIZ et al., 2017; KERBAUY, 2019). Com relação ao Al observam-se reduções nos teores médios em CC, nos tratamentos M1 $\left(0,45 \mathrm{cmol}_{\mathrm{c}} \mathrm{dm}^{-3}\right)$ e M5 $\left(0,32 \mathrm{cmol}_{\mathrm{c}} \mathrm{dm}^{-3}\right)$ e, em SC, no tratamento M2 $\left(0,48 \mathrm{cmol}_{\mathrm{c}}\right.$ $\left.\mathrm{dm}^{-3}\right)$. 
Tabela 5 - Valores médios para o desdobramento da interação dupla significativa entre método de recuperação (M) e calagem e escarificação superficial do solo (CE), em relação ao sódio (Na), com oito e dezesseis meses e ao alumínio (Al), após dezesseis meses de implantação do experimento ${ }^{1}$.

\begin{tabular}{|c|c|c|c|c|c|c|}
\hline \multirow[t]{4}{*}{$\mathrm{M}^{2}$} & \multicolumn{6}{|c|}{$\overline{\mathrm{CE}^{3}}$} \\
\hline & $\mathrm{CC}$ & $\mathrm{SC}$ & $\mathrm{CC}$ & $\mathrm{SC}$ & $\mathrm{CC}$ & $\mathrm{SC}$ \\
\hline & \multicolumn{4}{|c|}{$\mathrm{Na}\left(\mathrm{mg} \mathrm{dm}^{-3}\right)$} & \multicolumn{2}{|c|}{$\mathrm{Al}\left(\mathrm{cmol}_{\mathrm{c}} \mathrm{dm}^{-3}\right)$} \\
\hline & \multicolumn{2}{|c|}{8 meses } & \multicolumn{2}{|c|}{16 meses } & \multicolumn{2}{|c|}{16 meses } \\
\hline M1 & $6,67 \mathrm{aA}$ & $3,67 \mathrm{bB}$ & $6,00 \mathrm{aA}$ & $4,27 \mathrm{aA}$ & $0,45 \mathrm{bBC}$ & $0,78 \mathrm{aA}$ \\
\hline M2 & $5,17 \mathrm{aA}$ & $4,50 \mathrm{aA}$ & $7,38 \mathrm{aA}$ & $3,43 \mathrm{bB}$ & $0,78 \mathrm{aA}$ & $0,48 \mathrm{bB}$ \\
\hline M3 & $6,67 \mathrm{aA}$ & $6,00 \mathrm{aA}$ & $6,67 \mathrm{aA}$ & $4,95 \mathrm{aA}$ & $0,67 \mathrm{aAB}$ & $0,87 \mathrm{aA}$ \\
\hline M4 & $6,17 \mathrm{aA}$ & $4,00 \mathrm{aAB}$ & $3,23 \mathrm{bA}$ & $3,90 \mathrm{aA}$ & $0,75 \mathrm{aA}$ & $0,82 \mathrm{aA}$ \\
\hline M5 & $5,00 \mathrm{aA}$ & $2,33 \mathrm{bB}$ & $3,65 \mathrm{bA}$ & $2,67 \mathrm{cA}$ & $0,32 \mathrm{bC}$ & $0,82 \mathrm{aA}$ \\
\hline \multicolumn{2}{|l|}{$\mathrm{CV}_{\mathrm{M}}(\%)$} & & \multicolumn{2}{|c|}{28,17} & \multicolumn{2}{|c|}{25,65} \\
\hline \multicolumn{2}{|l|}{$\mathrm{CV}_{\mathrm{CE}}(\%)$} & & \multicolumn{2}{|c|}{20,40} & \multicolumn{2}{|c|}{30,60} \\
\hline \multicolumn{7}{|c|}{ 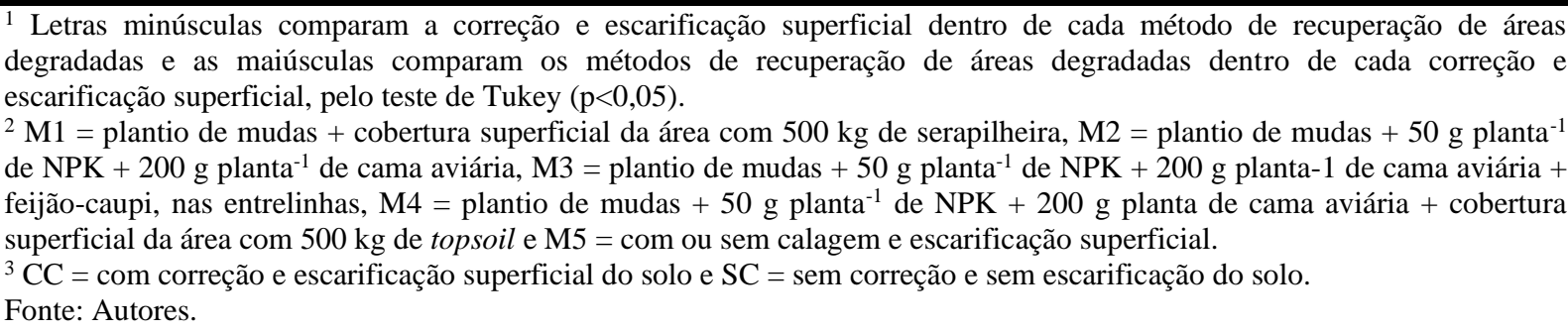 } \\
\hline
\end{tabular}

Pelos dados da Tabela 6, verifica-se interação dupla significativa entre CE x Ps para os teores médios de Al, Ca e $\mathrm{Ca}+\mathrm{Mg}$. Assim sendo, dentro dos tratamentos de CE, verificam-se reduções nos teores de Al, dentro do tratamento Ps, na camada de 0 a $10 \mathrm{~cm}$ de profundidade, no tratamento $\mathrm{CC}$, após oito $\left(0,24 \mathrm{cmol}_{\mathrm{c}} \mathrm{dm}^{-3}\right)$ e dezesseis $\left(0,46 \mathrm{cmol}_{\mathrm{c}} \mathrm{dm}^{-3}\right) \mathrm{meses}$ sendo essas equivalentes a 60,0 e 42,5\%, respectivamente, em relação ao tratamento Ps, na camada de 10 a $20 \mathrm{~cm}$ de profundidade. Dentro de cada tratamento de CE, constatou-se comportamento similar aos observados para o tratamento CC. O tratamento SC não foi influenciado significativamente, em cada tratamento de Ps, nas camadas de 0 a $10 \mathrm{~cm}$ e 10 a $20 \mathrm{~cm}$ de profundidades, nos dois períodos de avaliação (Tabela 6). 
Tabela 6 - Valores médios para os desdobramentos da interação dupla significativa entre calagem e escarificação superficial do solo $(\mathbf{C E})$ e profundidades do solo $(\mathrm{Ps}$, em $\mathrm{cm})$, em relação ao alumínio $(\mathrm{Al})$, cálcio $(\mathrm{Ca})$ e cálcio + magnésio $(\mathrm{Ca}+\mathrm{Mg})$, após oito e dezesseis meses da implantação do experimento ${ }^{1}$.

\begin{tabular}{|c|c|c|c|c|}
\hline \multirow[t]{4}{*}{$\mathrm{CE}^{2}$} & \multicolumn{4}{|c|}{$\mathrm{Ps}^{3}, \mathrm{em} \mathrm{cm}$} \\
\hline & $0-10$ & $10-20$ & $0-10$ & $10-20$ \\
\hline & \multicolumn{4}{|c|}{$\mathrm{Al}\left(\mathrm{cmol}_{\mathrm{c}} \mathrm{dm}^{-3}\right)$} \\
\hline & \multicolumn{2}{|c|}{8 meses } & \multicolumn{2}{|c|}{16 meses } \\
\hline $\mathrm{CC}$ & $0,24 \mathrm{bB}$ & $0,64 \mathrm{aA}$ & $0,46 \mathrm{bB}$ & $0,73 \mathrm{aA}$ \\
\hline $\mathrm{SC}$ & $0,60 \mathrm{aA}$ & $0,66 \mathrm{aA}$ & $0,80 \mathrm{aA}$ & $0,71 \mathrm{aA}$ \\
\hline $\mathrm{CV}_{\mathrm{CE}}(\%)$ & \multicolumn{2}{|c|}{35,29} & \multicolumn{2}{|c|}{30,60} \\
\hline $\mathrm{CV}_{\mathrm{Ps}}(\%)$ & \multicolumn{2}{|c|}{20,62} & \multicolumn{2}{|c|}{20,89} \\
\hline & \multicolumn{4}{|c|}{$\mathrm{Ca}\left(\mathrm{cmol}_{\mathrm{c}} \mathrm{dm}^{-3}\right)$} \\
\hline $\mathrm{CC}$ & $0,82 \mathrm{aA}$ & $0,19 \mathrm{aB}$ & $0,47 \mathrm{aA}$ & $0,19 \mathrm{aB}$ \\
\hline $\mathrm{SC}$ & $0,12 \mathrm{bA}$ & $0,09 \mathrm{aA}$ & $0,10 \mathrm{bA}$ & $0,05 \mathrm{bA}$ \\
\hline $\mathrm{CV}_{\mathrm{CE}}(\%)$ & \multicolumn{2}{|c|}{34,27} & \multicolumn{2}{|c|}{39,56} \\
\hline \multirow[t]{2}{*}{$\mathrm{CV}_{\mathrm{Ps}}(\%)$} & \multicolumn{2}{|c|}{29,26} & \multicolumn{2}{|c|}{21,34} \\
\hline & \multicolumn{4}{|c|}{$\mathrm{Ca}+\mathrm{Mg}\left(\mathrm{cmol}_{\mathrm{c}} \mathrm{dm}^{-3}\right)$} \\
\hline $\mathrm{CC}$ & $1,21 \mathrm{aA}$ & $0,25 \mathrm{aB}$ & $0,71 \mathrm{aA}$ & $0,31 \mathrm{aB}$ \\
\hline $\mathrm{SC}$ & $0,23 \mathrm{bA}$ & $0,17 \mathrm{aA}$ & $0,13 \mathrm{bA}$ & $0,09 \mathrm{aA}$ \\
\hline $\mathrm{CV}_{\mathrm{CE}}(\%)$ & \multicolumn{2}{|c|}{33,07} & \multicolumn{2}{|c|}{33,65} \\
\hline $\mathrm{CV}_{\mathrm{Ps}}(\%)$ & \multicolumn{2}{|c|}{13,13} & \multicolumn{2}{|c|}{15,95} \\
\hline
\end{tabular}

Ainda, na Tabela 6, observam-se reduções significativas $(\mathrm{p}<0,05)$ nos teores médios de Ca $\left(0,12 \mathrm{cmol}_{\mathrm{c}} \mathrm{dm}^{-3}\right) \mathrm{no}$ tratamento SC, aos oito meses, na camada de 0 a $10 \mathrm{~cm}$ de profundidade e, após dezesseis meses constataram-se comportamento semelhante, em ambas as profundidades. Os maiores teores de Ca foram observados no tratamento CC, de 0,82 $\mathrm{cmol}_{\mathrm{c}} \mathrm{dm}^{-3}$ e $0,47 \mathrm{cmol}_{\mathrm{c}} \mathrm{dm}^{-3}$ de Ca, na camada de 0 a $10 \mathrm{~cm}$ de profundidade, nos dois períodos de avaliação do experimento. Observa-se que a prática da calagem foi essencial para a diminuição dos teores de Al na camada de 0-10 cm, tendo em vista a reação química do calcário no solo que resulta na neutralização do Al (Caires et al., 2004; Bambolim et al., 2015; Vargas; Marques, 2017).

A análise do desdobramento da interação CE x Ps demonstra que, os teores de $\mathrm{Ca}+\mathrm{Mg}$ foram reduzidos dentro dos tratamentos de $\mathrm{CE}$, cujos valores dessas reduções corresponderam à 81,0 e $81,7 \%$ no tratamento $\mathrm{SC}$, na camada de 0 a $10 \mathrm{~cm}$ de profundidade, respectivamente, nos dois períodos de avaliação. Dentro de cada tratamento de CE, obteve-se o mesmo 
comportamento apresentado pelo atributo químico Ca. Na camada de 0,0 a 0,1 m de profundidade, constatou-se, no tratamento $\mathrm{CC}$, os maiores teores de $\mathrm{Ca}+\mathrm{Mg}\left(1,21 \mathrm{e}\right.$ 0,71 $\mathrm{cmol}_{\mathrm{c}} \mathrm{dm}^{-3}$, respectivamente), nos dois períodos avaliados (Tabela 6).

Com exceção do $\mathrm{Na}$, o comportamento dos teores médios dos atributos químicos referentes ao $\mathrm{Al}$, $\mathrm{Ca}$ e $\mathrm{Ca}+\mathrm{Mg}$, no solo construído, após a extração de seixo, nas camadas de 0 a $10 \mathrm{~cm}$ e 10 a $20 \mathrm{~cm}$ de profundidades, variaram em: Al: 0,24 a 0,66 $\mathrm{cmol}_{\mathrm{c}} \mathrm{dm}^{-3}$ e 0,46 a 0,80 $\mathrm{cmol}_{\mathrm{c}} \mathrm{dm}^{-3}$; Ca: 0,12 a $0,82 \mathrm{cmol}_{\mathrm{c}} \mathrm{dm}^{-3}$ e 0,05 a $0,47 \mathrm{cmol}_{\mathrm{c}} \mathrm{dm}^{-3}$ e Ca $+\mathrm{Mg}$ : 0,17 a $1,21 \mathrm{cmol}_{\mathrm{c}}$ $\mathrm{dm}^{-3}$ e 0,09 a $0,71 \mathrm{cmol}_{\mathrm{c}} \mathrm{dm}^{-3}$, respectivamente após oito e dezesseis meses da implantação do experimento.

\section{Conclusão}

Em geral, os teores de nutrientes e MOS, no solo construído após extração de seixo a céu aberto e submetido a tratamentos de revegetação, foram menores do que os obtidos no solo sob vegetação secundária.

Entre os tratamentos de revegetação, mostraram-se mais responsivos às combinações da aplicação de calcário dolomítico na base de $1.500 \mathrm{~kg} / \mathrm{ha}$, escarificação superficial do solo construído, adição de camada de $5 \mathrm{~cm}$ de espessura de topsoil ou serrapilheira, seguido do plantio de mudas das espécies botânicas usadas.

O uso da técnica de revegetação mostrou-se promissora, porém, em virtude do processo de recuperação da fertilidade do solo ser lento, é necessário o acompanhamento em longo prazo.

Estudos futuros voltados ao aumento das espessuras das camadas de topsoil e serrapilheira usadas para recuperação de áreas degradadas pela mineração de seixo e à avaliação do tempo que a camada de topsoil fica exposta às condições de ambiente, após a sua retirada para iniciar o processo de extração de seixo a céu aberto, devem ser realizados para melhor compreensão da dinâmica dos nutrientes no solo.

\section{Referências}

Bambolim A. Caione, G. Souza, N. F. Seben-Junior, G. F. \& Ferbonink, G. F. (2015). Calcário líquido e calcário convencional na correção da acidez do solo. Revista de Agricultura Neotropical, 2(3), 34-38. https://doi.org/10.32404/rean.v2i3.277

Barros, D. A. Coelho Junior, M. G. Oliveira, A. L. Silva Neto, E. C. (2018). Matéria orgânica e agregação do solo em áreas sobre influência da mineração de bauxita na região do planalto de Poços de Caldas, MG. Agropecuária Científica no Semiárido, 14(2), 160-167. http://doi.org/10.30969/acsa.v14i2.1018

Barbosa, J. C. \& Maldonado Junior, W. (2015). AgroEstat - sistema para análises estatísticas de ensaios agronômicos. FCAV/UNESP.

Borga, T. \& Campos, R. F. F. (2017). Proposta de recuperação de uma área degradada pela atividade de extração de basalto no município de Caçador, Santa Catarina. Revista Geonorte, 8(29), 23-37. https://doi.org/10.21170/geonorte.2017.V.8.N.29.23.37

Brady, N. C. \& Weil, R. R. (2013). Elementos da natureza e propriedades dos solos. Bookman Editora LTDA.

Caires, E. F. Kusman, M. T. Barth, G. Garbuio, F. J. \& Padilha, J. M. (2004). Alterações químicas do solo e resposta do milho à calagem e aplicação de gesso. Revista Brasileira de Ciência do Solo, 28(1), 125-136. https://doi.org/10.1590/S0100-06832004000100013

EMBRAPA. (2017). Manual de Métodos de Análise de Solo. Embrapa.

Gonçalves, J. R. M. R. Martins, F. B. S. \& Correia, R. M. (2020). Reutilização de Topsoil: uma solução sustentável na restauração de áreas degradadas. Brazilian Journal of Development, 6(5), 28258-28267, 2020. Https://doi.org/10.34117/bjdv6n5-320

Hartwig, G. I. Oliveira, A. C. Carvalho, F. I. F. Bertan, I. Silva, J. A. G. Schmidt, D. A. M.; Valério, I. P. Maia, L. C. Fonseca, D. A. R. \& Reis, C. E. S. (2007). Mecanismos associados à tolerância ao alumínio em plantas. Semina: Ciências Agrárias, 28(2). 219-228.

IBRAM. (2021). Setor Mineral. http://www.ibram.org.br/.

Kerbauy, G. B. (2019). Fisiologia vegetal. Guanabara Koogan.

Lima, K. D. R. Chaer, G. M. Raws, J. R. C. Mendoça \& V. Resende, A. S. (2015). Seleção de espécies arbóreas para revegetação de áreas degradadas por mineração de piçarra na caatinga. Revista Caatinga, 28(1), 203-213.

Neri, A. V. Soares, M. P. Meira, Neto, J. A. A. \& Dias, L. E. (2011). Espécies de Cerrado com potencial para recuperação de áreas degradadas por mineração de ouro, Paracatu-MG. Revista Árvore, 35(4), 907-918. https://doi.org/10.1590/S0100-67622011000500016

Longo, R. M. Ribeiro, A. Í. \& Melo, W. J. (2011). Uso da adubação verde na recuperação de solos degradados por mineração na floresta amazônica. Bragantia, 70(1), 139-146. https://doi.org/10.1590/S0006-87052011000100020 
Research, Society and Development, v. 10, n. 6, e12110615594, 2021

(CC BY 4.0) | ISSN 2525-3409 | DOI: http://dx.doi.org/10.33448/rsd-v10i6.15594

Pacheco, N. A. \& Bastos, T. X. (2001). Caracterização climática do município de Capitão Poço-PA. Embrapa Amazônia Oriental.

Rangel-Vasconcelos, L. G. T. Kato, O. R. \& Vasconcelos, S. S. (2012). Matéria orgânica leve do solo em sistema agroflorestal de corte e trituração sob manejo de capoeira. Pesquisa Agropecuária Brasileira, 47(8), 1142-1149. https://doi.org/10.1590/S0100-204X2012000800015

Reis, D. A. Lima, C. L. R. \& Pauletto, E. A. (2014). Resistência tênsil de agregados e compressibilidade de um solo construído com plantas de cobertura em área de mineração de carvão em Candiota, RS. Revista Brasileira de Ciência do Solo, 38(2), 669-678. https://doi.org/10.1590/S0100-06832014000200031

Sauma Filho, M. Ruivo, M. L. P. Alves, J. D. N. Conceição, H. E. O. Costa, M. L. P. Rocha Junior, J. A. L. Moraes, K. A. \& Oliveira, T. C. M. (2021). Macrofauna de áreas recuperadas após extração de seixo na região Amazônica. Brazilian Journal of Development, 7(4), 40229-40245. https://doi.org/ $10.34117 / \mathrm{bjdv} 7 \mathrm{n} 4-471$

Sauma Filho, M. Ruivo, M. L. P. Conceição, H. E. O. Viegas, I. J. M. Gonçalves, A. C. S.; Teixeira, O. M. M.; Oliveira, J. N. \& Galvão, R. M. (2020). Atributos químicos do solo construído após a extração de seixo em Capitão Poço, Pará, Brasil. Brazilian Journal of Development, 6(9), 64608-64623. https://doi.org/10.34117/bjdv6n9-047

Silva, I. A. Campagna, A. R. \& Lipp-Nissinen, K. H. (2018). Recuperação de áreas degradadas por mineração: uma revisão de métodos recomendados para garimpos. Pesquisas em Geociências, 45(3), e0691. https://doi.org/10.22456/1807-9806.91386

Taiz, L. Zeiger, E. MØler, I. M. \& Murphy, A. (2017). Fisiologia e desenvolvimento vegetal. Artmed.

Vargas, G. \& Marques, R. (2017). Crescimento e nutrição de angico e canafístula sob calagem e gessagem. Floresta e ambiente, 24, 1-10. http://doi.org/10.1590/2179-8087.010216

Yada, M. M. Mingotte, F. L. C. Melo, W. J. Melo, G. P. Melo, V. P. Longo, R. M. \& Ribeiro, A. Í. (2015). Atributos químicos e bioquímicos em solos degradados por mineração de estanho e em fase de recuperação em ecossistema amazônico. Revista Brasileira de Ciência do Solo, 39(3), 714-724. https://doi.org/10.1590/01000683rbcs20140499

Walkley, A. \& Black, I. A. (1934). An examination of the Degtjareff method for determining soil organic matter and a proposed modification of the chromic acid titration method. Soil Science, Baltimore, 37(1), 29-38. 